\title{
A Study on the Influence of the Service Quality of Container Terminal on the Reuse Intention
}

\section{컨테이너 터미널의 서비스 품질이 재이용 의도에 미치는 영향에 관한 연구}

Jinseub Kim ${ }^{1}$, Hakyun Kim $^{2}$

김진습 ${ }^{1}$, 김하균 ${ }^{2}$

${ }^{I}$ Doctoral Student, Graduate School of Information Systems, Pukyong National Univ., Korea, junhici@naver.com

${ }^{2}$ Professor, Division of Business, Pukyong National Univ., Korea, kimhk@pknu.ac.kr

Corresponding author: Hakyun Kim

\begin{abstract}
Currently, Northeast Asian countries, which are the center of global logistics, have entered a competitive system in terms of national survival strategy by pushing for logistics herb. If the good relationship with existing customers is maintained by enhancing the satisfaction of shipping companies that use container terminals, it can attract new potential customers, but, if customers who use container terminals are dissatisfied, it can be eliminated from logistics-oriented competition. This study is based on SERVQUAL model and classified the service quality types of container terminals into reliability, reactivity, guarantee, empathy, tangible, and accessibility as the cause variables that affect the satisfaction of shipping companies. The results of the study are the following. First, the reliability had a significant effect on the satisfaction of shipping company. Second, reactivity had a significant effect on the satisfaction of shipping company. Third, guarantee had a significant effect on the satisfaction of shipping company. Fourth, empathy had a significant effect on the satisfaction of shipping companies. Fifth, tangible had a significant effect on the satisfaction of shipping companies. Sixth, accessibility had a significant effect on the satisfaction of shipping companies. Seventh, the satisfaction of shipping companies had a significant effect on intention to reuse.
\end{abstract}

Keywords: Container Terminal, Service Quality, Shipping Company Satisfaction, Reuse intention

요약: 현재 세계 물류의 중심인 동북아시아 국가들은 물류 허브화를 추진함으로써 국가 생존전략 차원에서 경쟁체제에 돌입한 상태이다. 컨테이너 터미널을 이용하는 고객인 선사의 만족도를 제고하여 기존 고객과의 우호적인 관계가 유지된다면, 새로운 잠재고객을 유치할 수 있지만, 컨테이너 터미널을 이용하는 고객들에게 불만족을 준다면, 물류 중심 경쟁에서 도태될 수 있다. 본 연구는 SERVQUAL 모형을 기반으로 선사의 만족도에 영향을 미치는 원인변수로 컨테이너 터미널의 서비스 품질 유형을 신뢰성, 반응성, 보장성, 공감성, 유형성, 접근성으로 구분하였다. 연구결과는 다음과 같다. 첫째, 신뢰성은 선사 만족도에 유의적인 영향을 미쳤다. 둘째, 반응성은 선사 만족도에 유의적인 영향을 미쳤다. 셋째, 보장성은 선사

Received: March 11, 2021; $1^{\text {st }}$ Review Result: April 26, 2021; $2^{\text {nd }}$ Review Result: June 15, 2021 Accepted: July 31, 2021 
만족도에 유의적인 영향을 미쳤다. 넷째, 공감성은 선사 만족도에 유의적인 영향을 미쳤다. 다섯째, 유형성은 선사 만족도에 유의적인 영향을 미쳤다. 여섯째, 접근성은 선사 만족도에 유의적인 영향을 미쳤다. 일곱째, 선사 만족도는 재이용 의도에 유의적인 영향을 미쳤다.

핵심어: 컨테이너 터미널, 서비스 품질, 선사 만족도, 재이용 의도

\section{1. 서론}

현재 세계 물류의 중심인 동북아시아 국가들은 물류 허브화를 추진함으로써 국가 생존 전략 차원에서 경쟁체제에 돌입한 상태이다. 우리나라 역시 동북아시아의 관문이 되기 위해 여러 부문에 걸쳐 물류 중심 정책이 진행중이다. 이러한 물류 중심 정책의 핵심은 컨테이너 터미널이라고 할 수 있다. 컨테이너 터미널이 가지는 중계기능은 고용과 산업 자원의 재생산을 촉진시키며, 경제활동을 활성화시키는 등 지역경제에서 더 나아가 국가 경제에 활성화를 가져다 줄 중요한 자산이기 때문이다[1]. 기업 간의 경쟁이 치열해지고 기업에 대한 정부 규제가 완화되면서 많은 기업들은 차별화를 통해 생존해 나가기 위한 방법으로 고객들에게 높은 수준의 서비스 품질 전달을 위해 노력하고 있다[2].

지금까지 컨테이너 터미널의 개발 정책은 터미널 고객에 대한 서비스 품질 보다는 물 리적인 시설의 확충과 물류비용의 절감에 주력하여 왔다. 시장경쟁이 치열해질수록 물리 적인 시설과 물류비용의 절감은 평준화되어 한계에 도달하고 있다. 따라서 서비스 품질 향상을 통해 고객들의 만족과 경쟁우위를 확보하는 전략은 그 중요성이 상대적으로 부각 되고 있다.

기존에 이루어진 컨테이너 터미널의 서비스 품질에 관한 연구는 그 정의 및 유형을 중 심으로 연구되고 있다[3]. 본 연구에서는 SERVQUAL(Service + Quality) 모형을 기반으로 선사의 만족도에 영향을 미치는 원인변수로 컨테이너 터미널의 서비스 품질의 유형을 신 뢰성, 반응성, 보장성, 공감성, 유형성, 접근성으로 구분하였으며, 선사의 재이용 의도에 영향을 미치는 영향요인으로는 선사의 만족도를 채택하였다. 선사 임직원을 대상으로 한 컨테이너 터미널의 서비스 품질 요인에 대한 실증 연구는 매우 드문 게 현실이다. 본 연 구를 통하여 치열한 생존경쟁 환경에 처해 있는 컨테이너 터미널이 한층 더 높은 서비스 품질을 제공하여 경쟁우위를 확보하는데 이바지 하고자 한다.

\section{2. 이론적 배경}

\section{1 서비스 품질}

일반적으로 서비스 품질은 “전달된 서비스가 고객의 기대와 얼마나 일치하는가의 정 도”로 정의된다[4][5]. PZB는 “고객이 받을 것이라고 기대하는 서비스의 정도와 실제적으 로 수행된 서비스의 성과를 비교해 나타나는 차이” 로 정의하였다[6]. 후속 연구에서 $\mathrm{PZB}$ 는 서비스 품질이 “유형성, 신뢰성, 확신성, 반응성, 공감성”의 다섯 가지 차원으로 구성된다는 SERVQUAL 모형을 제시하였다[7]. 


\subsection{1 신뢰성}

신뢰성이란 약속된 서비스를 어김없이 정확하고 성실하게 수행할 수 있는 능력을 말한다[6][7]. 컨테이너 터미널에서 제공하는 서비스 품질 중 스케줄의 신뢰성은 선박의 대형화가 가속화되고 항만 간 경쟁이 치열해지면서 고객들의 터미널 선택에 매우 중요한 요인이 되고 있다. 접안 대기시간이 길어지거나 예정된 스케줄을 지키지 못하고 하역 사고가 자주 발생한다면 해당 터미널 이용에 대한 불안이 커진다. 즉, 해당 터미널에 대한 신뢰성이 떨어져 불신이 높아질 것이다. 그 결과 선사는 해당 터미널에 기항을 기피하게 된다. 따라서 서비스 운영체제가 고객을 최우선으로 고려하면서 약속을 잘 지키는 서비스를 수행할 것이라고 믿을 수 있도록 신뢰성과 믿음을 주어야 한다[3].

\subsection{2 반응성}

반응성은 다양한 고객들을 도우려는 의지와 그 고객 각각에 대한 적절한 서비스의 제공을 의미한다. 서비스를 제공하는 기업의 종사자들이 제공하는 서비스의 즉시 배달, 서비스의 신속한 처리 및 조치, 서비스의 적시 제공을 말하며 이는 곧 서비스를 제공하는 종업원들의 준비성과 자발성을 말한다[6]. 컨테이너 터미널에서 반응성의 경우, 다양한 고객에게 서비스를 제공하는 터미널 종사자들의 태도와 관련된 것이다. 즉, 예의 바르고 친절한 행동, 해당 업무에 대한 지식이 풍부한지, 다양한 고객들 각각에 대하여 관심을 가지는지, 해당 서비스를 신속하게 제공하는지 등을 의미한다[8].

\subsection{3 보장성}

보장성은 다양한 고객들의 니즈가 터미널 종사자들이 가지고 있는 지식 및 능력으로 어려움이나 불편함 없이 달성할 수 있도록 노력하는 태도를 의미한다. 터미널 종사자들은 다양한 고객들에게 성실하고 친절한 자세로 응대해야 하며 원활한 의사소통으로 유연하게 대처해야 한다[7]. 즉, 터미널 종사자들의 노하우 및 공손함과 자신감 및 신뢰를 증진시키는 능력을 말한다.

\subsection{4 공감성}

공감성은 다양한 고객에 대한 배려와 각각의 고객에게 개별적으로 관심을 가질 수 있는 준비가 되어 있는 정도 및 자세를 의미한다[7]. 터미널 종사자들은 화물 특성에 따른 다양한 고객들의 니즈를 고객들이 요구하기 전에 관심을 가지고 이해할 수 있도록 노력해야 한다. 여러 가지 문제 발생 시 항상 진지한 태도로 고객들의 사소한 요구에도 배려하며 응대함으로써 고객들과 친밀한 유대감을 형성하는 것이 중요하다[9].

\subsection{5 유형성}

유형성은 서비스 제공에 대한 외형적인 모습을 의미한다. 컨테이너 터미널에서의 유형성이란 물리적인 환경의 상태인 터미널의 시설이나 장비, 터미널 종사자들의 인상을 의미하는 인적 요소, 터미널의 원활한 운영을 담당하는 네트워크 연계망 등의 외형적인 단서를 말한다[10]. 이러한 물적 요소가 잘 완비되어 있는 터미널의 경우, 고객 만족도에 긍정적인 영향을 미친다.

\subsection{6 접근성}

접근성이란 최대한 많은 사용자가 어떠한 제품이나 서비스 등에 접근해 편리하게 
이용할 수 있는 정도를 의미한다. 제품이나 서비스의 접근성이 높다는 것은 많은 사용자가 어떠한 것을 이용하는데 있어서 편리하다는 것을 뜻한다. 반대로 접근성이 낮다는 것은 사용자가 해당 제품이나 서비스를 이용하기 불편하거나, 이용하기가 불가능하다는 것이다. 따라서 접근성을 높이기 위해서는 초기 설계 단계에서 사용자의 여러가지 특성을 고려하게 된다. 컨테이너 터미널에서의 접근성은 선사의 만족도에 많은 영향을 미치는 요인이다. 충분한 시간적 화물 분류 및 집하 시설의 공간적 접근성, 화물 관련 정보시스템적 접근성, 그리고 운송수단 연계를 통한 지리적 접근성 등이 그 요인이다[11].

\section{2 선사 만족도}

만족도란 고객이 특정한 제품 그리고 서비스의 품질에 대한 고객 자신이 지각하는 결 과로 나타나는 감성적 반응이다. 따라서 객관적인 품질과 고객 자신이 지각하는 품질은 반드시 일치하지는 않는다. 이러한 고객만족은 소비경험으로 얻어진 결과와 평가의 과정, 이 두 가지 관점에서 정의할 수 있다. 소비경험으로 얻어진 결과는 만족도를 개념화한 것이다. 고객 자신이 치른 대가가 적절한지 혹은 적절하지 않은지에 대해 인지한 상태라 고 정의하였다. 반면, 평가의 과정에 만족도를 정의한 것으로 소비 경험이 최소한 기대되 었던 것보다 좋았다는 평가라고 정의하였다.

본 연구에서는 다양한 고객들이 컨테이너 터미널의 서비스를 제공받고 그 후 고객의 만족도가 선행하는 변수의 서비스 품질과 어떤 관계를 나타내는지 확인하기 위한 연구이므로 만족도에 대한 두 가지 관점 중 결과에 중점을 두고 연구를 진행한다.

\section{3 재이용 의도}

고객이 느끼는 만족도는 결과적으로 고객의 재구매 의도에 영향을 미치게 된다. 만족한 고객이 불만족한 고객보다 재구매 할 가능성이 높음을 증명하였다. 구매 의도는 미래 재 구매 의도에 적응 수준의 역할을 하며, 소비경험으로 얻어진 만족도는 재구매 의도에 영 향을 미친다는 점을 증명하였다[12]. 만족도가 높을수록 평가대상에 긍정적인 태도를 보 이며, 긍정적인 태도는 재구매 의도에 영향을 미치는 것이다[13]. 이러한 연구 결과들은 본 연구의 컨테이너 터미널의 서비스를 경험 한 후 고객들의 만족도가 재이용 의도에 유 의미한 영향을 미친다는 가설의 설정 근거를 제공해 준다.

고객은 특정한 제품이나 서비스를 이용한 후, 그 성과와 구매 전 기대를 비교하여 구매한 제품이나 서비스에 대하여 만족도를 형성하며, 만족도가 높은 고객은 다시 그 제품이나 서비스를 구매하고자 하는 재구매 의도를 갖게 된다. 반대로 만족도가 낮은 고객은 그 제품이나 서비스를 더 이상 구매를 하지 않고 여러가지 불평 행동을 가지게 되므로 서비스 품질이 고객의 재구매 의도를 갖게 하는 중요한 요인이다.

\section{3. 연구설계}

\section{1 연구모형}

컨테이너 터미널의 서비스 품질은 물리적인 유형의 품질보다 더욱 중요하다. 선사의 
재이용 의도를 높이기 위해서는 선사 만족도가 선행되어야 한다. 제안한 연구모형은 컨테이너 터미널이 제공하는 서비스 품질과 선사 만족도, 그리고 컨테이너 터미널을 재이용하려는 충성도 관계를 분석하는 데 중점을 두었다. SERVQUAL 모형[7]을 기반으로 컨테이너 터미널이 제공하는 서비스 품질을 결정하는 요인으로 신뢰성, 반응성, 보장성, 공감성, 유형성, 접근성을 선정하였다. 선행연구를 바탕으로 한 연구 모형은 [그림 1]과 같다.

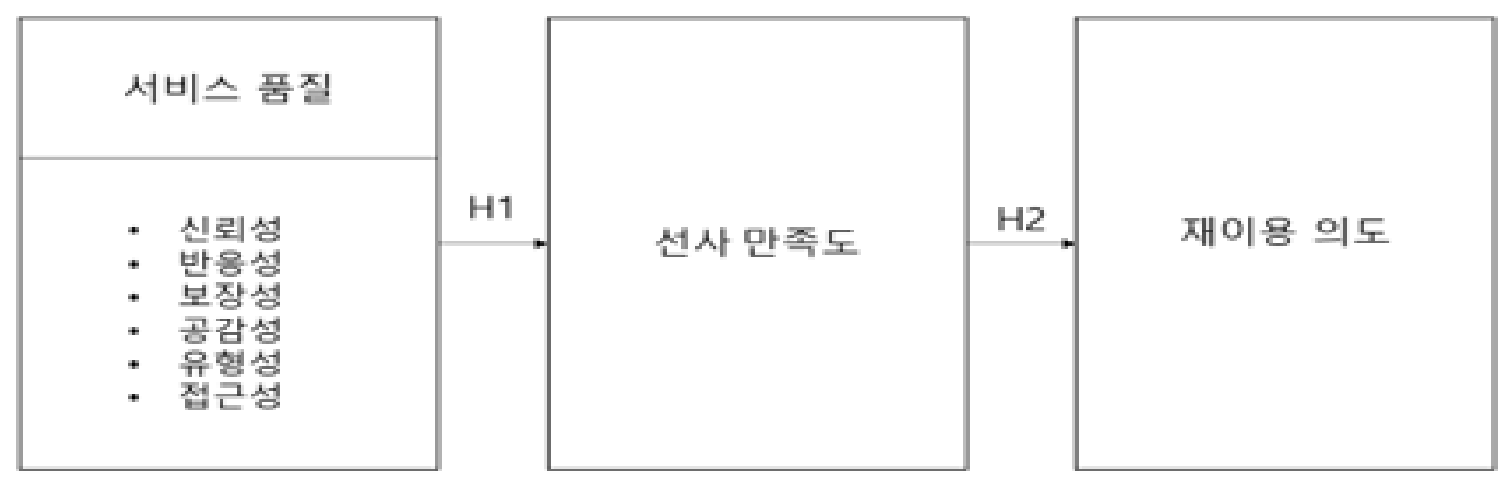

[그림 1] 연구모형

[Fig. 1] Research Model

\section{2 연구가설}

연구자마다 컨테이너 터미널의 서비스 품질 유형을 다양하게 분류하여 제시하는데, 일 반적으로 국내외 서비스 품질은 신뢰성, 반응성, 보장성, 공감성, 유형성, 접근성, 유의성, 가치성 등으로 구분하여 연구되었다[14]. 본 연구에서는 선행연구를 기반으로 다음과 같 은 가설을 설정하였다.

가설 H1-1 신뢰성은 선사 만족도에 유의적인 영향을 미칠 것이다.

가설 H1-2 반응성은 선사 만족도에 유의적인 영향을 미칠 것이다.

가설 H1-3 보장성은 선사 만족도에 유의적인 영향을 미칠 것이다.

가설 H1-4 공감성은 선사 만족도에 유의적인 영향을 미칠 것이다.

가설 H1-5 유형성은 선사 만족도에 유의적인 영향을 미칠 것이다.

가설 H1-6 접근성은 선사 만족도에 유의적인 영향을 미칠 것이다.

만족도는 선사가 서비스를 제공받고 치른 대가가 적절한지 아닌지 인지하는 상태[12]로 컨테이너 터미널의 서비스 품질에 대한 선사 만족도가 높을수록 재이용 의도가 높아지는 결과를 보였다[15]. 본 연구에서는 다음과 같은 가설을 설정하였다.

가설 $\mathrm{H} 2$ 선사 만족도는 재이용 의도에 유의적인 영향을 미칠 것이다.

\section{4. 실증분석 및 결과}

가설검정을 위해 SPSS 22.0과 Smart PLS 2.0을 사용하여 집중타당성과 판별타당성을 
검증하였다. 요인적재 값, Cronbach' a, 구성신뢰도(Composite Reliability) 및 각 요인의 평균분산추출 값(Average Variance Extraction)을 검증하였다. 요인적재 값은 0.6 이상, Cronbach' a 값은 0.7 이상, 구성신뢰도 값은 0.7 이상, 및 0.5 이상의 분산추출지수 값이 일반적으로 인정된다.

\section{1 자료수집 및 표본의 특성}

총 120 명의 컨테이너 터미널을 이용하는 선사의 직원들이 본 설문조사에 참여하였다. 응답자의 성별은 남자(75.6\%)가 여자 $24.4 \%)$ 보다 많았으며, 연령은 40 대(41.7\%)가, 직급은 과장급 $(28.3 \%)$ 이, 근무경력은 10 년 15 년차 $(30 \%)$ 가 가장 많았다. 이용항로는 기타(35.3\%)가 가장 많았으며, 중국(17.6\%), 미주(15.1\%), 유럽과 동남아(13.4\%), 일본(5\%) 순이었다. 이용항만은 부산항(80\%)이, 취급화물은 컨테이너 화물(69.2\%)이 가장 많았다.

\section{2 자료의 분석방법}

신뢰도와 타당도를 검증하기 위해 요인분석을 실시하였으며, Cronbach's Alpha 계수를 통해서 검증하였다. 집중 타당성의 결과는 [표 1], 판별타당성의 결과는 [표 2]와 같다.

[표 1] 신뢰도 및 집중 타당성 분석 결과

[Table 1] Reliability and Internal Consistency Results

\begin{tabular}{|c|c|c|c|c|}
\hline 변수 & 요인적재 값 & $\mathrm{AVE}$ & C. R. & Cronbach's a \\
\hline \multirow{4}{*}{ 신뢰성 } & 0.862 & \multirow{4}{*}{$0 . .726$} & \multirow{4}{*}{0.913} & \multirow{4}{*}{0.874} \\
\hline & 0.868 & & & \\
\hline & 0.853 & & & \\
\hline & 0.823 & & & \\
\hline \multirow{4}{*}{ 반응성 } & 0.852 & \multirow{4}{*}{0.755} & \multirow{4}{*}{0.925} & \multirow{4}{*}{0.891} \\
\hline & 0.897 & & & \\
\hline & 0.908 & & & \\
\hline & 0.814 & & & \\
\hline \multirow{4}{*}{ 보장성 } & 0.885 & \multirow{4}{*}{0.789} & \multirow{4}{*}{0.937} & \multirow{4}{*}{0.911} \\
\hline & 0.892 & & & \\
\hline & 0.897 & & & \\
\hline & 0.878 & & & \\
\hline \multirow{4}{*}{ 공감성 } & 0.884 & \multirow{4}{*}{0.724} & \multirow{4}{*}{0.913} & \multirow{4}{*}{0.872} \\
\hline & 0.862 & & & \\
\hline & 0.781 & & & \\
\hline & 0.872 & & & \\
\hline \multirow{2}{*}{ 유형성 } & 0.883 & \multirow{2}{*}{0.765} & \multirow{2}{*}{0.929} & \multirow{2}{*}{0.898} \\
\hline & 0.867 & & & \\
\hline
\end{tabular}




\begin{tabular}{|c|c|c|c|c|}
\hline & 0.893 & & & \\
\hline & 0.856 & & & \\
\hline \multirow{4}{*}{ 접근성 } & 0.769 & \multirow{4}{*}{0.707} & \multirow{4}{*}{0.906} & \multirow{4}{*}{0.861} \\
\hline & 0.842 & & & \\
\hline & 0.869 & & & \\
\hline & 0.880 & & & \\
\hline \multirow{4}{*}{ 선사 만족도 } & 0.889 & \multirow{4}{*}{0.815} & \multirow{4}{*}{0.946} & \multirow{4}{*}{0.924} \\
\hline & 0.899 & & & \\
\hline & 0.910 & & & \\
\hline & 0.914 & & & \\
\hline \multirow{4}{*}{ 재이용 의도 } & 0.917 & \multirow{4}{*}{0.847} & \multirow{4}{*}{0.957} & \multirow{4}{*}{0.940} \\
\hline & 0.923 & & & \\
\hline & 0.936 & & & \\
\hline & 0.905 & & & \\
\hline
\end{tabular}

[표 2] 상관관계 및 판별타당성 분석 결과

[Table 2] Correlation and Discriminant Validity

\begin{tabular}{|c|c|c|c|c|c|c|c|c|c|}
\hline 변수 & $\mathrm{AVE}$ & 1 & 2 & 3 & 4 & 5 & 6 & 7 & 8 \\
\hline 신뢰성 & 0.725 & $\mathbf{0 . 8 5 1}$ & & & & & & & \\
\hline 반응성 & 0.755 & 0.845 & $\mathbf{0 . 8 6 9}$ & & & & & & \\
\hline 보장성 & 0.789 & 0.718 & 0.762 & $\mathbf{0 . 8 8 8}$ & & & & & \\
\hline 공감성 & 0.724 & 0.764 & 0.809 & 0.820 & $\mathbf{0 . 8 5 1}$ & & & & \\
\hline 유형성 & 0.765 & 0.797 & 0.844 & 0.709 & 0.797 & $\mathbf{0 . 8 7 5}$ & & & \\
\hline 접근성 & 0.707 & 0.713 & 0.742 & 0.663 & 0.668 & 0.781 & $\mathbf{0 . 8 4 1}$ & & \\
\hline 선사 만족도 & 0.815 & 0.831 & 0.865 & 0.798 & 0.849 & 0.865 & 0.795 & $\mathbf{0 . 9 0 3}$ & \\
\hline 재이용 의도 & 0.847 & 0.805 & 0.808 & 0.769 & 0.782 & 0.796 & 0.750 & 0.894 & $\mathbf{0 . 9 2 0}$ \\
\hline
\end{tabular}

\section{3 연구모형의 검중}

구조 모형은 Smart PLS 2.0을 사용하였으며 구조 모형을 통해서 연구모형의 변수들 간의 경로계수와 결정계수 $\left(\mathrm{R}^{2}\right)$ 결과 값을 도출하였다. $\mathrm{R}^{2}$ 값이 0.26 이상이면 적합도가 높은 편이며, $0.26 \sim 0.13$ 이면 중간이다. 0.13이하는 적합도가 낮은 것으로 표시할 수 있다[16]. 


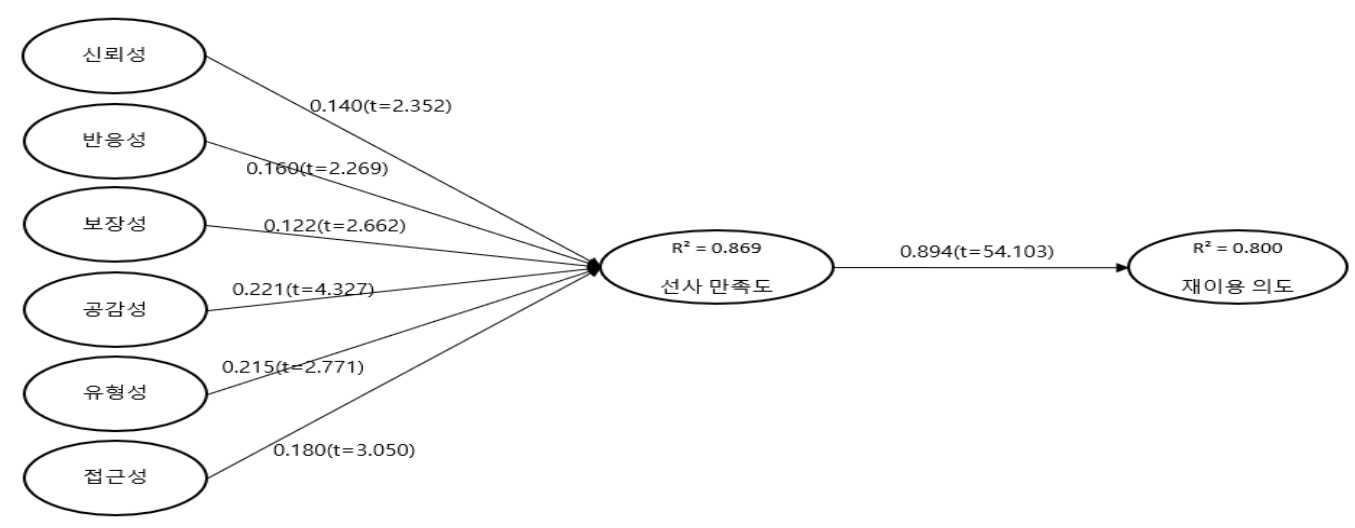

[그림 2] 모형 분석 결과

[Fig. 2] The Results of Research Model

제안한 가설 $\mathrm{H} 1, \mathrm{H} 2$ 는 채택되었다. 첫째, 가설 H1-1의 “신뢰성은 선사 만족도에 영향을 미칠 것이다” 라는 가설은 채택되었다. 신뢰성과 선사 만족도 $(\beta=0.140, \mathrm{t}=2.352, \mathrm{p}<0.05)$ 는 유의한 영향이 있는 것으로 나타났다. 둘째, 가설 H1-2의 “반응성은 선사 만족도에 영향을 미칠 것이다" 라는 가설은 채택되었다. 반응성과 선사 만족도 $(\beta=0.160, \mathrm{t}=2.269$, $\mathrm{p}<0.05)$ 는 유의한 영향이 있는 것으로 나타났다. 셋째, 가설 H1-3의 “보장성은 선사 만족도에 영향을 미칠 것이다" 라는 가설은 채택되었다. 보장성과 선사 만족도 $(\beta=0.122$, $\mathrm{t}=2.662, \mathrm{p}<0.05)$ 는 유의한 영향이 있는 것으로 나타났다. 넷째, 가설 H1-4의 "공감성은 선사 만족도에 영향을 미칠 것이다" 라는 가설은 채택되었다. 공감성과 선사 만족도 $(\beta=0.221, \mathrm{t}=4.327, \mathrm{p}<0.05)$ 는 유의한 영향이 있는 것으로 나타났다. 다섯째, 가설 $\mathrm{H} 1-$ 5 의 "유형성은 선사 만족도에 영향을 미칠 것이다" 라는 가설은 채택되었다. 유형성과 선사 만족도 $(\beta=0.215, \mathrm{t}=2.771, \mathrm{p}<0.05)$ 는 유의한 영향이 있는 것으로 나타났다. 여섯째, 가설 H1-6의 "접근성은 선사만족도에 영향을 미칠 것이다" 라는 가설은 채택되었다. 접근성과 선사 만족도 $(\beta=0.180, \mathrm{t}=3.050, \mathrm{p}<0.05)$ 는 유의한 영향이 있는 것으로 나타났다. 일곱째, 가설 $\mathrm{H} 2$ 의 “선사 만족도는 재이용 의도에 영향을 미칠 것이다" 라는 가설은 채택되었다. 선사 만족도와 재이용 의도 $(\beta=0.894, \mathrm{t}=54.103, \mathrm{p}<0.05)$ 는 유의한 영향이 있는 것으로 나타났다.

[표 3] 가설검정 결과 요약

[Table 3] Results of Hypothesis Tests for the Research Model

\begin{tabular}{|c|c|c|c|}
\hline 가설 경로 & 표준화 계수(ß) & t-value & 채택 유무 \\
\hline H1.1: 신뢰성 $\rightarrow$ 선사 만족도 & 0.140 & 2.352 & 채택 \\
\hline H1.2: 반응성 $\rightarrow$ 선사 만족도 & 0.160 & 2.269 & 채택 택 \\
\hline H1.3: 보장성 $\rightarrow$ 선사 만족도 & 0.122 & 2.662 & 채택 \\
\hline H1.4: 공감성 $\rightarrow$ 선사 만족도 & 0.221 & 4.327 & 채택 \\
\hline $\mathrm{H} 1.5:$ 유형성 $\rightarrow$ 선사 만족도 & 0.215 & 2.771 & 책 택 \\
\hline $\mathrm{H} 1.6:$ 접근성 $\rightarrow$ 선사 만족도 & 0.180 & 3.050 & 54.103 \\
\hline $\mathrm{H} 2:$ 선사 만족도 $\rightarrow$ 재이용 의도 & 0.894 & & \\
\hline
\end{tabular}




\section{5. 결론}

본 연구는 컨테이너 터미널의 서비스 품질(신뢰성, 반응성, 보장성, 공감성, 유형성, 접 근성)이 선사 만족도를 매개로 재이용 의도에 어떠한 영향을 미치는지를 분석하기 위한 실증연구이다. 본 연구를 통하여 컨테이너 터미널의 서비스 품질이 선사 만족도와 재이 용 의도에 유의한 영향을 미친다는 것이 실증적으로 검증되었다. 연구의 결과를 요약하 면 첫째, 컨테이너 터미널의 서비스 품질이 선사 만족도에 영향을 미친다는 가설 $\mathrm{H} 1$ 은 채택되었다. 서비스 품질 요인의 신뢰성, 반응성, 보장성, 공감성, 유형성, 접근성은 선사 만족도에 유의한 영향을 미쳤다. 둘째, 선사 만족도는 재이용 의도에 유의한 영향을 미친 다는 가설 $\mathrm{H} 2$ 는 채택되었다. 이는 선행연구에서도 같은 결과를 보이고 있다[12-15].

연구의 시사점은 다음과 같다. 첫째, 선사는 컨테이너 터미널의 서비스 품질 중 공감성, 접근성, 유형성, 보장성, 신뢰성, 반응성 순으로 높은 만족도를 보이고 있다. 둘째, 선사 만족도가 재이용 의도에 높은 영향을 미치고 있다는 것이 확인되었다. 이러한 결과는 서 비스를 제공하는 컨테이너 터미널의 입장에서 외국어 관련 의사소통이 능한 직원의 능력 뿐만 아니라 고객들의 불만을 수렴하고 고객들과 강한 유대감을 형성해야 한다는 것을 의미하고 있다. 또한 충분한 화물의 분류 및 집하 시설을 확보하고, 고객들이 원하는 시 간에 소통할 수 있어야 하며, 명확한 화물 관련 정보를 제공하고, 편리한 운송수단과의 연계도 필요함을 말해 주고 있다.

본 연구를 기반으로 컨테이너 터미널의 서비스 품질에 관한 연구는 향후 더욱 세밀하 게 진행되어야 한다. 특히, 재이용 의도에 영향을 미치는 서비스 품질의 결정요인들이 더 많이 개발되고 검증되어야 할 것이다.

\section{References}

[1] E. Kim, An Empirical Study on the Service Quality and Customer Satisfaction of Container Terminal in Korea, Department of Foreign Trade, The School Sung Kyun Kwan University, Doctoral Dissertation, (2005)

[2] T. Phillip, G. R. Desouza, T. G. Bradelye, The Strategic Management of Service Quality, Strategic Planning Institute, (1985)

[3] B. Kim, A Study on the Perception of the Service Quality at Container Terminals in Korea, Ocean Policy Research, (2000), Vol.15, No.2, pp.89-122.

[4] C. Gronroos, A Service Quality Model and Its Marketing Implications, European Journal of Marketing, (1984), Vol.18, No.4, pp.36-44, https://doi.org/10.1108/EUM0000000004784

[5] C. Gronroos, Service Quality: The Six Criteria of Good Service Quality, Review of Business, (1988), Vol.3, pp.12.

[6] A. Parasuraman, V. A. Zeithaml, L. L. Berry, A Conceptual Model of Service Quality and Its Implications for Future Research, Journal of Marketing, (1985), Vol.49, No.4, pp.41-50, https://doi.org/10.2307/1251430

[7] A. Parasuraman, V. A. Zeithaml, L. L. Berry, SERVQUAL: a multi-item scale for measuring consumer perceptions of the service quality, Journal of Retailing, (1988), Vol.64, No.1, pp.12-40.

[8] B. Kim, The Study of Effect of Logistics Service Quality Dimensions on Customer Satisfaction, Department of Business Administration, The Graduate School of Inha University, Doctoral Dissertation, (2006), pp.11-14.

[9] L. Sylvie, J. L. Chandon, C. Orsingher, An Empirical Study of Servqual's Dimensionality, The Service Industries Journal, (1998), Vol.18, No.2, pp.16-44, https://doi.org/10.1080/02642069800000017

[10] E. Park, H. Kim, K. Lee, A study on the Evaluation of the Logistics Service Quality of Container Terminal Operators, 
Journal of Korea Port Economic Association, (2009), Vol.25, No.1, pp.47-62, UCI : G704-001504.2009.25.1.010

[11] C. Kim, S. Lee, Design and Application of Service Quality Measurement Instrument in Bulk Ports, Journal of Shipping and Logistics, (2011), Vol.27, No.4, pp.545-561, DOI : 10.37059/tjosal.2011.27.4.545

[12] P. A. Labarbara, D. Mazursky, A Longitudinal Assessment of Consumer Satisfaction/Dissatisfaction : The Dynamic Aspect of the Cognitive Process, Journal of Marketing Research, (1983), Vol.20, No.4, pp.393-404, DOI: https://doi.org/10.2307/3151443

[13] M. J. Bitner, Evaluating Service Encounters : The Effects of Physical Surroundings and Employee Responses, Journal of Marketing Research, (1990), Vol.54, No.2, pp.69-82, https://doi.org/10.2307/1251871

[14] R. K. Teas, Expectations, Performance Evaluation and Consumers Perceptions of Quality, Journal of Marketing, (1993), Vol.57, No.4, pp.18-34, https://doi.org/10.2307/1252216

[15] J. Shi, A study on the Service Quality and Customer Loyalty of Shanghai port Container Terminals in China, Department of International, Trade Graduate School Cheongju University, Doctoral Dissertation, (2014), pp.50-81.

[16] J. Cohen, Statistical Power Analysis for the Behavioral Science(2nd), New York: Lawrence Erlbaum Associates, (1988), pp.90-100. 